\title{
An application of DEA based Malmquist productivity index in university performance analysis
}

\author{
Marzieh Rahimian $^{\mathrm{a}^{*}}$ and Mehdi Soltanifar ${ }^{\mathrm{b}}$
}

${ }^{a}$ Department of Management and Accounting, Islamic Azad University, Semnan Branch, Semnan, Iran

${ }^{b}$ Assistance Professor, Department of Management and Accounting, Islamic Azad University, Semnan Branch, Semnan, Iran

\begin{tabular}{l}
\hline A R T I C L E I N F O \\
\hline Article history: \\
Received March 25, 2012 \\
Received in revised format \\
17 October 2012 \\
Accepted 17 October 2012 \\
Available online \\
October 172012 \\
\hline Keywords: \\
Malmquist productivity index \\
Data envelopment analysis \\
Efficiency measurement
\end{tabular}

\section{A B S T R A C T}

\begin{abstract}
Measuring relative efficiency of various universities has been a subject for years. In fact, when there is a growing competition among educational units, it is important to find facts on each university for making managerial decisions. In this paper, we present an empirical study to measure the relative efficiencies among different private universities in Iran. The proposed study of this paper uses data envelopment analysis along with Malmquist productivity index to measure the relative efficiencies of these units over the period 2004-2007. The method uses three inputs including number of students, number of university professors and the number of employees. The model also includes the number of educated people as well as research outputs for outputs of the DEA model. The results indicate that there are some big gaps among various units in terms of the number of research products and the number of graduated students.
\end{abstract}

\section{Introduction}

For over three decades, data envelopment analysis (DEA) has been a technique for measuring the relative efficiency of decision making units (DMUs) with multiple inputs and multiple outputs (Charnes et al., 1978, 1994; Banker et al., 1984). The method has become popular in university performance measurement (Prichard , 1990; Youn \& Park, 2009; Roghanian \& Foroughi, 2010). In fact, there are literally various kinds of DEA methods such as constant return to scale, variable return to scale, etc. (Charles et al., 1994) but all them use a basic infrastructure where similar units are compared using some input and output factors. The idea of measuring efficiency tries to find a special weight for each input and output and the resulted model is formulated as an extension of a linear programming problem. DEA methods have been implemented for non-for-profit organizations where similar units are operating with various input/output and there is basically no revenue. Governmental agencies such as schools, hospitals, public libraries are instances of these cases. Nevertheless, the * Corresponding author.

E-mail addresses: m.rahimian.edu@gmail.com (M. Rahimian) 
implementation of DEA has been expanded for revenue based organizations where financial results are just small part of performance measurement. Malmquist index can also be used along with DEA method for monitoring the performance over a specific period. Garcia and Palomares (2008) used Malmquist index to measure the relative efficiencies of 43 governmental universities in Spain over the period of 1994-2004. The results of their survey demonstrated that efficiency improvement depended more on technological improvement than technical improvement.

Afonso and Santos (2008) employed data envelopment analysis to measure the relative efficiency scores for Portuguese public universities, using data mainly for 2003. The input measures were built from the number of teachers and from universities' spending while the outputs measures were associated with undergraduate success rate and on the number of doctoral dissertations. They used frontier analysis to separate universities that might qualify, as performing well from those were some improvement might be possible based on efficiency.

Avkiran (2001) discussed that performance indicators in the public sector can be criticized for being insufficient for analyzing efficiency and proposed DEA implementation to study the relative efficiency of Australian universities. The paper used three performance models including overall performance, performance on delivery of educational services, and performance on fee-paying enrolments. Using 1995 data and applying DEA method, they reported that the university sector was performing well on technical and scale efficiency but there was place for improving performance on fee-paying enrolments. According to their survey, more universities were operating at decreasing returns to scale, which means there is a potential to downsize.

The implementation of DEA helped identify the reference sets for inefficient institutions and objectively determined productivity improvements. The results were also valuable as benchmarking tool for educational administrators and help in more efficient allocation of scarce resources. When there is no precise of market mechanisms to price educational outputs, universities could use such alternative efficiency analysis methods for efficiency measurement. Abbott and Doucouliagos (2003) measured the relative efficiencies of various Australian universities based on the implementation of DEA method.

Chen and Ali (2004) used DEA-based Malmquist productivity index to measure the productivity change over time. The DEA-based Malmquist productivity index can be decomposed into two components including measuring the technical change and measuring the frontier shift. They provided an extension to the DEA-based Malmquist technique by further analyzing these two Malmquist components. Their proposed method not only reveals patterns of productivity change and suggests a new interpretation along with the managerial application of each Malmquist component, but also determines the strategy shifts of individual DMUs based on isoquant changes. The results suggest it can make judgments on whether or not such strategy shifts are favorable and promising. The implementation of the proposed model was used with a set of Fortune Global 500 Computer and Office Equipment companies over the period 1991-1997.

Johnes (2006) investigated the possibility of measuring efficiency in the context of higher education. Johnes (2006) explored the benefits and drawbacks of different methods for measuring efficiency in the higher education context and implemented DEA to a data set of more than 100 HEIs in England 
using data for the year 2000/01. Technical and scale efficiency in the English higher education sector appeared to be high on average.

There are other applications of DEA method for measuring the relative efficiencies of similar units. Khani et al. (2012), for instance, first used output oriented DEA to measure the relative efficiencies of nine hospitals in province of Ilam, located in west part of Iran. They used four types of employee namely specialists, physicians, technicians and other staffs as input parameters. The model also implemented the number of surgeries, hospitalized and radiography as the outputs of the proposed model and implemented supper efficiency technique to measure the relative efficiency of efficient units. Fallah et al. (2011) investigated DEA models for the estimation and improvement of organizational inputs and outputs in order to incorporate management and decision making processes. They proposed an empirical DEA method on banking sector by considering several financial and non-financial inputs and outputs. The relative efficiencies of various branches of banks were analyzed under various scenarios. The results showed that there were some non-financial items, which could change the overall performance of a unit along with other financial items, substantially. Najafi et al. (2011) presented a cause and effect two-stage BSC-DEA method for measuring the relative efficiency of organizations.

In this paper, we present an application of DEA method for measuring the relative efficiencies of various universities. The organization of this paper first presents details of problem statement in section 2 and the results are given in section 3 . The paper ends by concluding remarks in section 4 .

\section{Problem statement}

Let $x_{i j}$ be the inputs for a decision unit with $i=1, \ldots, m$ and $y_{r j}$ be the outputs with $r=1, \ldots, s$ and $j=1, \ldots, n$. Let $u_{i}$ and $v_{j}$ be the dual variables associated with $x_{i}$ and $y_{j}$, respectively. An output oriented DEA model is formulated as follows,

$$
\begin{gathered}
\min \theta-\varepsilon\left(\sum_{\mathrm{i}=1}^{\mathrm{m}} s_{i}^{-}+\sum_{\mathrm{r}=1}^{\mathrm{s}} s_{r}^{+}\right) \\
\text {subject to } \sum_{j=1}^{n} x_{i j} \lambda_{j}+s_{i}^{-}=\theta x_{i \circ}, \mathrm{i}=1,2, \ldots, \mathrm{m} \\
\sum_{j=1}^{n} y_{r j} \lambda_{j}-s_{r}^{+}=\mathrm{y}_{r \circ}, \quad \mathrm{r}=1,2, \ldots, \mathrm{s} \\
\lambda_{j}, s_{r}^{+}, s_{i}^{-} \geq 0
\end{gathered}
$$

In model (1) when $\theta^{*}=1$ then we have $s_{r}^{+^{*}}=s_{i}^{-*}=0$. Model (1) is the basis of traditional DEA and it is solved $j$ times to determine the relative efficiencies of various units. Note that the first constraint also becomes linear using a simple manipulation.

Problem (1) has been widely used for the past three decades and the results are commonly accepted as a tool to measure the relative efficiency of different units. However, when there is uncertainty with the inputs and the outputs, one may use different techniques to make sure that a small change on input/output data does not change the output rankings.

In many cases, we have more than one single efficient unit and in this case we can run the model proposed by Mehrabian et al. (2000) among efficient units to find the relative efficiency of these units. The model is as follows, 
$\max \sum_{r=1}^{s} u_{r} y_{r 0}-\sum_{i=1}^{m} v_{i} x_{i 0}$

subject to

$\sum_{r=1}^{s} u_{r} y_{r j}-\sum_{i=1}^{m} v_{i} x_{i j} \leq 0, j=1, \cdots, n, j \neq 0$

$\sum_{i=1}^{m} v_{i}+\sum_{r=1}^{s} u_{r}=1, r=1, \cdots, s$

$u_{r} \geq 0, v_{i} \geq 0, i=1, \cdots, m$.

One of the primary concerns on measuring the relative efficiency is to look for different types of efficiency improvement such as technical. When we intend to measure the efficiency over time, it is better to look for different components, which can be stated as Malmquist productivity index (Mohammadi \& Ranaei, 2011) stated as follows,

$M_{o}=\frac{D_{o}^{t+1}\left(X_{o}^{t+1}, Y_{o}^{t+1}\right)}{D_{o}^{t}\left(X_{o}^{t}, Y_{o}^{t}\right)}\left[\frac{D_{o}^{t}\left(X_{o}^{t+1}, Y_{o}^{t+1}\right)}{D_{o}^{t+1}\left(X_{o}^{t+1}, Y_{o}^{t+1}\right)} \bullet \frac{D_{o}^{t}\left(X_{o}^{t}, Y_{o}^{t}\right)}{D_{o}^{t+1}\left(X_{o}^{t}, Y_{o}^{t}\right)}\right]^{1 / 2}$.

In Eq. (3) $\left[\frac{D_{o}^{t}\left(X_{o}^{t+1}, Y_{o}^{t+1}\right)}{D_{o}^{t+1}\left(X_{o}^{t+1}, Y_{o}^{t+1}\right)} \bullet \frac{D_{o}^{t}\left(X_{o}^{t}, Y_{o}^{t}\right)}{D_{o}^{t+1}\left(X_{o}^{t}, Y_{o}^{t}\right)}\right]$ shows technological changes.

In this paper, we study the relative efficiencies of different educational systems based on the implementation of data envelopment analysis (DEA) over the period of 2004-2007. There are three inputs associated with the proposed method of this paper including number of students, number of university professors and the number of employees. The model also includes the number of educated people as well as research outputs.

In order to have a fair comparison we need to consider some weights for each input/output factor. In this study, we consider a weight of 11 for a $\mathrm{PhD}$ student, 10 for Master students, 8 for undergraduate students and 7 for a two year college program. The other input is university professors where we consider a relative weight of 120 for a full professor, a weight of 110 for each associate professor, a weight of 100 for assistant professor and finally a weight of 60 for regular trainees.

Another types of weights are considered for employees with various degrees where 11 is assigned for employees with $\mathrm{PhD}$ degree, 10 for any employee with master degree, 8 for any employees with bachelor degree, 7 for those who have a two-year college degree, 6 for those employees who have completed high schools and finally 4 for employees who did not finish high schools.

In our study, we consider a weight five for the number of papers indexed by institute for scientific information (ISI), 4 is a relative weight for papers confirmed by Ministry of education. We have also considered relative weights of 3 and 2 for ordinary developmental papers and general working papers, respectively. The study considers relative weights of 1 and 2 for domestic and international conferences, respectively. Finally, the study considers relative weights of 20 and 10 for original and translated books, respectively. 


\section{The results}

As we have explained before, the proposed study uses two methods of DEA and Malqiemst to find the performances of different units. Table 1 shows details of efficiency estimation using DEA method.

\section{Table 1}

The relative efficiencies of various universities using BCC DEA method

\begin{tabular}{lcccc}
\hline & \multicolumn{4}{c}{ Relative efficiency over the period of 2004-2007 } \\
\hline Name & 2004 & 2005 & 2006 & 2007 \\
\hline Azad Shahr & 0.966 & 1 & 1 & 0.963 \\
Bandar Gaz & - & - & 0.972 & 1 \\
Damghan & 0.467 & 0.323 & 0.402 & 0.775 \\
Semnan & 0.755 & 0.773 & 0.661 & 0.909 \\
Aliabad Katool & 1 & 1 & 1 & 1 \\
Gorgan & 1 & 1 & 1 & 1 \\
Shahrood & 1 & 1 & 1 & 1 \\
Garmsar & 1 & 1 & 1 & 1 \\
Gonbad Kavoos & - & - & - & - \\
Minoo Dasht & - & - & - & 1 \\
Mehdi Shahr & - & - & - & \\
\hline
\end{tabular}

In Table 1, when a university does not have any output in a particular year we do not report any efficiencies for these units. In addition, since we have more than one efficient unit in many cases we use Mehrabian et al. (2000) method for ranking all units and Table 2 summarizes the results of our survey.

\section{Table 2}

The relative efficiencies of various universities using BCC DEA method

\begin{tabular}{lcccc}
\hline & \multicolumn{4}{c}{ Relative efficiency over the period of 2004-2007 } \\
\hline Name & 2004 & 2005 & 2006 & 2007 \\
\hline Azad Shahr & 4 & 4 & 4 & 6 \\
Bandar Gaz & - & - & 5 & 4 \\
Damghan & 7 & 7 & 8 & 8 \\
Semnan & 6 & 6 & 6 & 10 \\
Aliabad Katool & 2 & 2 & 2 & 7 \\
Gorgan & 1 & 1 & 1 & 2 \\
Shahrood & 3 & 3 & 3 & 9 \\
Garmsar & 5 & 5 & 7 & 3 \\
Gonbad Kavoos & - & - & - & - \\
Minoo Dasht & - & - & - & 5 \\
Mehdi Shahr & - & - & - & \\
\hline
\end{tabular}

Based on the results of DEA ranking we calculate changes in efficiency, technology and calculate Malmquist index and Table 3, Table 4 and Table 5 present details of our findings, 
Table 3

Changes in efficiency, technology and Malmquist index over the period of 2004-2005

\begin{tabular}{|c|c|c|c|c|}
\hline & \multicolumn{2}{|c|}{ Changes in } & Malmquist & Progress \\
\hline Name & Efficiency & Technology & 2006 & Regression \\
\hline Azad Shahr & 5.95 & 0.32 & 1.9 & Regression \\
\hline Bandar Gaz & - & - & - & No output \\
\hline Damghan & 4.76 & 0.42 & 2.02 & Regression \\
\hline Semnan & 4.26 & 0.40 & 1.71 & Progress \\
\hline Aliabad Katool & 5.46 & 0.34 & 1.85 & Regression \\
\hline Gorgan & 1 & 0.67 & 0.67 & Regression \\
\hline Shahrood & 1 & 0.37 & 0.37 & Regression \\
\hline Garmsar & 5.31 & 0.28 & 1.49 & Progress \\
\hline Gonbad Kavoos & - & - & - & No output \\
\hline Minoo Dasht & - & - & - & No output \\
\hline Mehdi Shahr & - & - & - & No output \\
\hline
\end{tabular}

As we can observe from the results of Table 3, there were five units including Azad Shahr, Damghan Aliabad Katool, Gorhan and Shahrood, where are inefficient. On the other hand, two units of Semnan and Garmsar were improving units. In addition, there were four unit with no output results and we could not perform any judgment.

Table 4

Changes in efficiency, technology and Malmquist index over the period of 2005-2006

\begin{tabular}{lcccc}
\hline & \multicolumn{2}{c}{ Changes in } & Malmquist & Progress \\
\hline Name & Efficiency & Technology & 2006 & Regression \\
\hline Azad Shahr & 1 & 0.96 & 0.96 & Regression \\
Bandar Gaz & - & - & - & No output \\
Damghan & 0.803 & 1.22 & 0.98 & Regression \\
Semnan & 1.12 & 0.98 & 1.10 & Progress \\
Aliabad Katool & 1 & 0.98 & 0.98 & Regression \\
Gorgan & 0.48 & 1 & 0.48 & Regression \\
Shahrood & 1 & 0.932 & 0.932 & Regression \\
Garmsar & 1 & 1.03 & 1.03 & Progress \\
Gonbad Kavoos & - & - & - & No output \\
Minoo Dasht & - & - & - & No output \\
Mehdi Shahr & - & - & - & No output \\
\hline
\end{tabular}

According to the results of Table 4, there are still four units, which did not provide their research achievement and we could not compare their performance with other firms. Nevertheless, there are only two units, which represent efficient units and the other units are still in regression state.

\section{Table 5}

Changes in efficiency, technology and Malmquist index over the period of 2006-2007

\begin{tabular}{lcccc}
\hline & \multicolumn{2}{c}{ Changes in } & Malmquist & Progress \\
\hline Name & Efficiency & Technology & 2006 & Regression \\
\hline Azad Shahr & 1.038 & 0.93 & 0.965 & Regression \\
Bandar Gaz & 0.972 & 1.01 & - & No output \\
Damghan & 0.51 & 1.52 & 0.98 & Regression \\
Semnan & 0.72 & 1.25 & 0.77 & Progress \\
Aliabad Katool & 1 & 0.98 & 0.908 & Regression \\
Gorgan & 1 & 0.49 & 0.98 & Regression \\
Shahrood & 1 & 0.927 & 0.49 & Regression \\
Garmsar & 1 & 1.02 & 0.927 & Progress \\
Gonbad Kavoos & - & - & 1.02 & No output \\
Minoo Dasht & - & - & - & No output \\
Mehdi Shahr & - & - & & No output \\
\hline
\end{tabular}


Again, the results of Table 5 show that two units of Semnan and Garmsar are the best ones as they were in previous years and the other units did not attempt to change their status, significantly.

\section{Conclusion}

In this paper, we have presented an empirical investigation to measure the relative efficiencies of various private universities in province of Semnan, Iran. The proposed study of this paper has gathered the necessary information of these units in terms of three inputs and two outputs. The results of measuring relative efficiencies have been compared in three consecutive years from 2004 to 2007 based on Malmquist productivity index. The method uses three inputs including number of students, number of university professors and the number of employees. The model also includes the number of educated people as well as research outputs for outputs of the DEA model. Based on the result of this survey, we can conclude that there is a need for many private schools to look into their research activities and try to increase their performance through publications.

\section{Acknowledgment}

The authors would like to thank the anonymous referees for their comments on earlier version of this paper.

\section{References}

Abbott, M., \& Doucouliagos, C. (2003). The efficiency of Australian universities: a data envelopment analysis. Economics of Education Review, 22, 89-97

Afonso, A., \& Santos, M. (2008). Students and Teachers: A DEA Approach to the Relative Efficiency of Portuguese Public Universities. ISEG-UTL Economics Working Paper No. 07/2005/DE/CISEP. Available at SSRN: http://ssrn.com/abstract=744464

Avkiran, K. (2001). Investigating technical and scale efficiencies of Australian universities through data envelopment analysis. Socio Economic Planning Sciences, 35, 57-80.

Banker, R.D., Charnes, A., Cooper, W.W. (1984). Some models for the estimation of technical and scale inefficiencies in Data Envelopment Analysis. Management Science, 30, 1078-1092.

Charnes, A., Cooper, W.W., Rhodes, E. (1978). Measuring the efficiency of decision making units. European Journal of Operational Research, 2, 429-444.

Charnes A, Cooper W. W., Lewin, A., Seiford, L. M. (1994). Data envelopment analysis: theory, methodology and applications. Massachusetts: Kluwer Academic Publishers.

Chen, Y., \& Ali, A.I. (2004). DEA Malmquist productivity measure: New insights with an application to computer industry. European Journal of Operational Research, 159, 239- 249.

Fallah, M., Aryanezhad, M.B., Najafi, S.E., \& Shahsavaripour, N. (2011). An empirical study on measuring the relative efficiency using DEA method: A case study of bank industry. Management Science Letters, 1(1), 49-56.

Garcia, A., \& Palomares, D. (2008). Evaluation of Spanish universities: Efficiency, technology and productivity change. Prime-Latin America Conference at Mexico City, September 24-26, 1-33.

Johnes, J. (2006). Data envelopment analysis and its application to the measurement of efficiency in higher education. Economics of Education Review, 25, 273-288.

Khani, F., Naderi, H., Zangeneh, M., \& Faseli, E. (2012). Measuring the relative efficiency of Ilam hospitals using data envelopment analysis. Management Science Letters, 2(4), 1189-1194.

Youn, J. W., \& Park, K. (2009). University development models and efficiency analysis. Journal of Service Science, 1, 9-30.

Mehrabian S., M., Alirezaee, Jahanshahloo, G., \& Amin, G.R. (2000). An assurance internal for non archimedean epsilon in DEA model. Operation Research, 48, 344-347.

Mohammadi, A., \& Ranaei, H. (2011). The application of DEA based Malmquist productivity index in organizational performance analysis. International Research Journal of Finance and Economics, 62, 68-76. 
344

Najafi, S.E., Ahmadi, S.A., Fallah, M., \& Shahsavaripour, N. (2011). A cause and effect two-stage BSC-DEA method for measuring the relative efficiency of organizations. Management Science Letters, 1(1), 41-48.

Prichard, R.D. (1990). Measuring and Improving Organizational Productivity. New York: Praeger Publishers.

Roghanian, E., \& Foroughi, A. (2010). An empirical study of Iranian regional airports using robust data envelopment analysis. International Journal of Industrial Engineering Computations, 1(1), 65-72. 